\title{
COMPLEMENT ACTIVATION BY HEPARIN-PROTAMINE COMPLEXES DURING CARDIOPULMONARY BYPASS: EFFECT OF C4A NULL ALLELE
}

Kaushik A. Shastri, $\mathrm{MD}^{\mathrm{a}}$

Gerald L. Logue, $\mathrm{MD}^{\mathrm{a}}$

Mont P. Stern, MD ${ }^{\mathrm{b}}$

Saif Rehman, MD

Syed Raza, MD $^{\circ}$
Objectives: The first objective was to determine the effect of inherited differences in the classic pathway complement protein $\mathrm{C} 4$ on complement activation by heparin-protamine complexes in cardiac surgery. Specifically, we hypothesized that patients with heterozygous $C 4 A$ null phenotype (AOBB), who have decreased amounts of $\mathrm{C} 4 \mathrm{~A}$, may have increased complement activation because of reduced clearance of heparin-protamine complexes. The second objective was to determine whether heparin-protamineinduced complement activation correlated with postoperative pulmonary shunt fractions. Methods: C4 typing was performed by agarose gel immunofixation and crossed immunoelectrophoresis. Complement activation was measured by radioimmunoassay of $\mathrm{C3a}$ and $\mathrm{C} 4 \mathrm{a}$ before cardiopulmonary bypass, after bypass, and after protamine infusion. Shunt fractions were calculated from blood gases. Results: Of the 79 patients, 18 expressed heterozygous $\mathrm{C4A}$ null allele (A0BB), 16 had heterozygous $\mathrm{C} 4 \mathrm{~B}$ null allele (AAB0), three had homozygous C4B null alleles (AA00), and the rest expressed both $\mathrm{C} 4 \mathrm{~A}$ and $\mathrm{C} 4 \mathrm{~B}$ alleles $(\mathrm{AABB})$. Patients with heterozygous C4A null allele had significantly increased plasma levels of C4a after protamine neutralization of heparin ( $\mathrm{C} 4 \mathrm{a}$ of $2862 \pm 375 \mathrm{ng} / \mathrm{ml}$; mean \pm standard error of the mean) when compared with patients with normal expression of $\mathrm{C} 4$ alleles $(\mathrm{AABB})(\mathrm{C} 4 \mathrm{a}$ of $1580 \pm 141 \mathrm{ng} / \mathrm{ml})$ or heterozygous C4B null allele (C4a $1526 \pm 208 \mathrm{ng} / \mathrm{mI}$ ). Pulmonary shunt fractions obtained after the operation correlated with the classic pathway complement activation by heparin-protamine complexes, but not with alternative pathway complement activation during cardiopulmonary bypass. Conclusions: Patients with heterozygous $\mathrm{C} 4 \mathrm{~A}$ null phenotype have increased complement activation by heparin-protamine complexes during cardiac operations, possibly because of their defective clearance. The classic pathway complement activation by heparin-protamine interaction correlates with postoperative pulmonary shunt fractions. (J Thorac Cardiovasc Surg 1997;114:482-8)
C omplement is activated by two distinct mechanisms during cardiac operations. It is activated by the alternative pathway during the cardiopulmonary bypass (CPB) procedure ${ }^{1}$ and by the classic

From the Medical Service, Department of Veterans Affairs, Western New York Health Care System, Buffalo, N.Y., and Department of Medicine, State University of New York at Buffalo; The Buffalo General Hospital and Department of Anesthesia, State University of New York at Buffalo ${ }^{\mathrm{b}}$; and The Buffalo General Hospital and Department of Cardiothoracic Surgery, State University of New York at Buffalo, ${ }^{c}$ Buffalo, N.Y.

This work was supported by grant R29-HL47858, funded by the National Heart, Lung, and Blood Institute and the Office of Research of Women's Health, the National Institutes of Health, pathway during protamine neutralization of circulating heparin at the end of $\mathrm{CPB} .{ }^{2,3}$ Previous studies show significant variations in complement activation produced by heparin-protamine complexes. ${ }^{2,3} \mathrm{Al}$ -

and also in part by the Richard E. Wahle Research Fund of the State University of New York at Buffalo, N.Y.

This work was performed at The Buffalo General Hospital and the Buffalo Veterans Administration Medical Center.

Received for publication Sept. 20, 1996; revisions requested Nov. 11, 1996; revisions received May 2, 1997; accepted for publication May 2, 1997.

Address for reprints: Kaushik A. Shastri, MD, 11 l-H, Veterans Administration Medical Center, 3495 Bailey Ave., Buffalo, NY 14215 .

12/1/83070 
though these variations can be due to as yet undefined perioperative factors, they may also reflect the differences in the ability of individual patients to activate complement in response to heparin-protamine complexes. Heparin-protamine complexes have similarities to immune complexes ${ }^{4,5}$ by virtue of the fact that they both activate complement by the classic pathway. Thus it is possible that inherited differences in an early-acting classic pathway complement component may account for this variability.

The fourth component of human complement plays a pivotal role in the classic pathway of complement activation and, thereby, also in the clearance of immune complexes. ${ }^{6}$ The human $\mathrm{C} 4$ gene is coded at two different loci in the major histocompatibility complex on chromosome 6 , and the major products of these loci are designated $\mathrm{C} 4 \mathrm{~A}$ and $\mathrm{C} 4 \mathrm{~B}{ }^{7}$ These two major isotypes (C4A and $\mathrm{C} 4 \mathrm{~B})$ differ in their biochemical and functional properties, ${ }^{8}$ with activated $\mathrm{C} 4 \mathrm{~B}$ having more hemolytic activity and activated $\mathrm{C} 4 \mathrm{~A}$ binding more to immune complexes. The $\mathrm{C} 4$ gene also displays significant polymorphism with expression of a null allele at the C4A site and C4B site occurring in approximately $20 \%$ and $23 \%$ of the population, respectively. ${ }^{7}$ Presence of a null allele (i.e., only a single copy of the active gene at either site) can be detected by crossed immunoelectrophoresis as approximately $50 \%$ reduction in that particular protein. ${ }^{9}$ Because the binding of activated $\mathrm{C} 4$ is important in clearance of immune complexes, partial deficiency of the $\mathrm{C} 4 \mathrm{~A}$, which preferentially binds to these complexes, can retard their clearance. ${ }^{6}$ The similarities between heparin-protamine complexes and immune complexes in terms of preferential activation of the classic pathway led us to examine the correlation between $\mathrm{C} 4$ phenotypes and the degree of complement activation seen in CPB and protamine neutralization of heparin. The degree of complement activation during CPB and that resulting from heparin-protamine interaction was also correlated with the postoperative pulmonary shunt fractions.

\section{Patients, materials, and methods}

After we had obtained approval by the institutional review board and informed consent from the patients, patients undergoing CPB for first-time coronary artery bypass grafting were entered in this case series. Inclusion criteria included normal preoperative arterial blood gases and renal function, as well as a cardiac ejection fraction of $45 \%$ or more. Patients were excluded if they had combined valvular and coronary artery disease or a history of myocardial infarction within the preceding 6 months.
Anesthesia was induced with sufentanil, pancuronium, and midazolam with patients breathing $100 \%$ oxygen. Porcine heparin at a dose of 300 units/kg body weight was administered before institution of CPB. Additional 3000to 5000-unit supplements of heparin were given to maintain the activated clotting time over 400 seconds as measured by a Sonoclot analyzer (Sienco, Inc., Morrison, Colo.). Myocardial protection was achieved with hypothermic crystalloid potassium cardioplegic solution and topical cold saline slush to maintain myocardial temperatures between $10^{\circ}$ and $15^{\circ} \mathrm{C}$. Cobe membrane oxygenators (Cobe Laboratories, Inc., Lakewood, Colo.) were used in all cases. On completion of the CPB procedure, protamine sulfate (10 $\mathbf{m g}$ for every 1000 units of heparin) was diluted in $100 \mathrm{ml}$ of $5 \%$ dextrose and administered over $7.7 \pm 2.4$ minutes (mean \pm standard deviation) via a peripheral vein.

Blood samples for C3a des Arg (C3a) and C4a des Arg (C4a) were obtained in tubes containing ethylenediaminetetraacetic acid before institution of CPB, at the end of $\mathrm{CPB}$ but before protamine infusion, and 10 minutes after protamine infusion. Blood samples were centrifuged at $4^{\circ} \mathrm{C}$ and plasma retrieved within 30 minutes of procurement. C3a and C4a assays were carried out with the use of radioimmunoassay kits from Amersham (Rockford, Ill.) per the manufacturer's instructions. All assays were done in triplicate, with the variation in results among triplicates being less than $10 \%$.

$\mathrm{C} 4$ isotype studies were performed from plasma samples obtained before the operation in tubes containing ethylenediaminetetraacetic acid according to previously described techniques. ${ }^{10}$ Isotypes were assigned by comparison to standards of known $\mathrm{C} 4$ isotypes according to accepted nomenclature. ${ }^{11}$ Null alleles were inferred by the reduction in the density of corresponding $\mathrm{C} 4 \mathrm{~A}$ or $\mathrm{C} 4 \mathrm{~B}$ band and confirmed in all cases by crossed immunoelectrophoresis performed according to previously described methods. ${ }^{9}$

Performing family studies to further define $\mathrm{C} 4$ phenotypes is not feasible in this older patient population. The methods used in our study allow us to identify single or double null alleles if they are confined to either the $\mathrm{C} 4 \mathrm{~A}$ or $\mathrm{C} 4 \mathrm{~B}$ locus. However, the simultaneous single null alleles at both loci (i.e., one C4AQ0 and one C4BQ0), which occur in approximately $3 \%$ of subjects, cannot be distinguished from a normal $\mathrm{C} 4$ phenotype without null alleles. Thus five possible $\mathrm{C} 4$ phenotype groups were deducible, which for convenience we have abbreviated as follows: (1) $\mathrm{AABB}=$ no detectable null alleles, (2) $\mathrm{A} 0 \mathrm{BB}=$ a single null allele (heterozygous) at $\mathrm{C} 4 \mathrm{~A}$ locus, (3) $00 \mathrm{BB}=$ a homozygous $\mathrm{C} 4 \mathrm{~A}$ null allele, (4) $\mathrm{AAB} 0=\mathrm{a}$ single null allele (heterozygous) at C4B locus, and (5) $\mathrm{AA} 00=\mathrm{a}$ homozygous $\mathrm{C} 4 \mathrm{~B}$ null allele. $\mathrm{A}$ and $\mathrm{B}$ in the preceding refer to any expressed allele of the respective isotype (i.e., A represents $\mathrm{A} 1$ through $\mathrm{A} 6$ and $\mathrm{B}$ represents B1, B2, or B3).

As a measure of postoperative pulmonary function, physiologic (pulmonary) shunt fractions were calculated from arterial and mixed venous blood gases obtained 6 to 8 hours and 16 to 18 hours after the operation. ${ }^{12}$

Differences with respect to $\mathrm{C} 4 \mathrm{a}$ and $\mathrm{C} 3 \mathrm{a}$ were evaluated by means of one-way analysis of variance separately for 


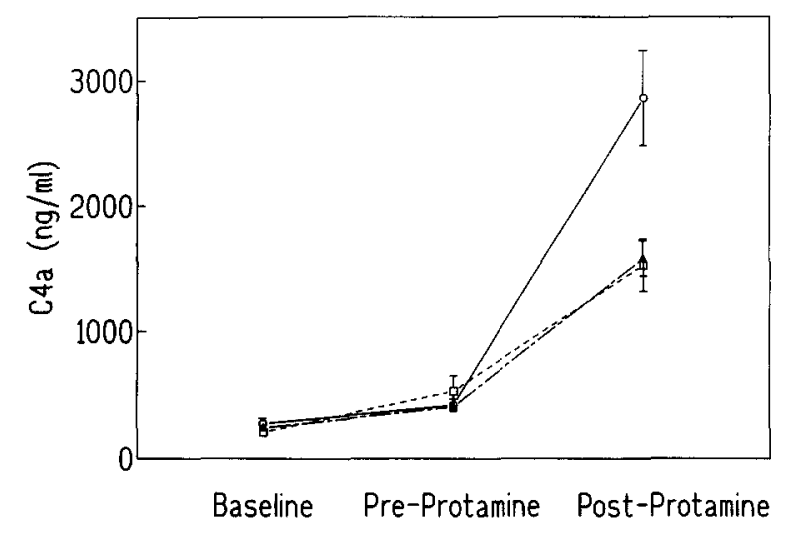

Fig. 1. Influence of $\mathrm{C} 4$ phenotype on complement activation during cardiac operations as measured by $\mathrm{C} 4 \mathrm{a}$ des Arg. C4a levels were measured at different time periods shown on the $\mathrm{X}$ axis; the baseline represents measurements before $\mathrm{CPB}$, pre-protamine indicates measurements at the end of CPB but before protamine, and postprotamine reflects the measurements obtained from blood samples collected 10 minutes after protamine administration. The triangular symbols joined by dashed lines represent patients with normal $\mathrm{C} 4$ phenotype (AABB), open circles with solid lines represent patients with single $\mathrm{C} 4 \mathrm{~A}$ null allele $(\mathrm{A} 0 \mathrm{BB})$, and square symbols with dotted lines show the data on patients with single $C 4 B$ null allele (AAB0). The error bars for each data point represent standard error of mean. The post-protamine $\mathrm{C} 4 \mathrm{a}$ levels for the $\mathrm{A} 0 \mathrm{BB}$ group were statistically different from those of the other two groups (see text).

the pre-protamine and post-protamine sampling times. The Scheffé multiple comparison procedure was used to detect differences between the $\mathrm{C} 4$ isotype groups. To better control for type I errors caused by performing tests at two different time points, we used a significance level of $2.5 \%$. A determination of the possible influence of other factors such as protamine dose, CPB time, age, and body surface area was also investigated by means of analysis of covariance with these factors as covariates. The strength of the association between shunt fractions and change in C4a and C3a was assessed by Pearson's product moment correlation coefficient. The possibility that other factors could account for the association between shunt fractions and C4a was assessed by determining the partial correlation coefficients. We adjusted for a number of factors, including age, protamine dose, CPB time, and body surface area. Statistical analyses were performed with SPSS for Windows (version 6.1.3, SPSS Inc., Chicago, Ill.). Descriptive statistics are expressed as mean \pm standard deviation. For group comparisons, the mean \pm standard error of the mean and $95 \%$ confidence intervals (CI) are provided.

\section{Results}

Of the 79 patients entered in the study, 54 were male and 25 were female. Their mean age $( \pm$ standard deviation) was $62.94 \pm 9$ years, they were supported by $\mathrm{CPB}$ for $80.0 \pm 33.4$ minutes, and they received $288.4 \pm 71.1 \mathrm{mg}$ of protamine. These parameters were not different among the $\mathrm{C} 4$ isotypes groups described herein. Only one patient required mechanical ventilation for greater than 24 hours.

As described in the Patients, materials, and methods section, $\mathrm{C} 4$ isotype studies were performed in all the patients in the study. Of these, 42 patients had no null alleles (AABB) $(53.16 \%), 18$ patients had one $\mathrm{C} 4 \mathrm{~A}$ null allele (A0BB) (22.78\%), 16 patients had one $\mathrm{C} 4 \mathrm{~B}$ null allele (AAB0) $(20.25 \%)$, and three patients had homozygous $\mathrm{C} 4 \mathrm{~B}$ null phenotype (AA00)(3.8\%). None of the patients in the study had homozygous C4A null phenotype (00BB). Because of the small number of patients, the homozygous C4B null group has not been included in the statistical analysis. Our results are comparable with previously reported phenotype frequencies. Awdeh and Alper, ${ }^{7}$ in a comparable general population, found $20 \%$ frequency of one C4A null allele, $23 \%$ of one $\mathrm{C} 4 \mathrm{~B}$ null allele, $1 \%$ for both $\mathrm{C} 4 \mathrm{~A}$ null alleles, and $2 \%$ for both $\mathrm{C} 4 \mathrm{~B}$ null alleles.

Complement activation by the classic pathway leads to an increase in both $\mathrm{C} 3 \mathrm{a}$ and $\mathrm{C} 4 \mathrm{a}$, whereas alternative pathway activation is reflected by increase in $\mathrm{C} 3 \mathrm{a}$ alone without corresponding increase in C4a. Figs. 1 and 2 show complement activation during cardiac operations as measured by $\mathrm{C} 4 \mathrm{a}$ and $\mathrm{C} 3 \mathrm{a}$ levels, respectively, in patients with different $\mathrm{C} 4$ phenotypes. The baseline $\mathrm{C} 3 \mathrm{a}$ and $\mathrm{C} 4 \mathrm{a}$ levels were similar in the three $\mathrm{C} 4$ isotype groups. Levels of $\mathrm{C} 3 \mathrm{a}$ and $\mathrm{C} 4 \mathrm{a}$ at the end of $\mathrm{CPB}$ but before protamine infusion were evaluated. C3a levels (Fig. 2) increased in all three groups, without a corresponding degree of change in C4a (Fig. 1), indicating complement activation predominantly by the alternative pathway during CPB. Protamine administration, on the other hand, led to increases in both $\mathrm{C} 3 \mathrm{a}$ and $\mathrm{C} 4 \mathrm{a}$ levels. As shown in Fig. 1, the post-protamine $\mathrm{C} 4 \mathrm{a}$ levels were $1580 \pm 141 \mathrm{ng} / \mathrm{ml}$ (mean \pm standard error of the mean; $95 \% \mathrm{CI}: 1295$ to $1865 \mathrm{ng} / \mathrm{ml}$ ) for the group with both $\mathrm{C} 4$ phenotypes present in full (AABB), $2862 \pm 375 \mathrm{ng} / \mathrm{ml}$ (95\% CI: 2069 to 3654 $\mathrm{ng} / \mathrm{ml}$ ) for the group with heterozygous C4A null phenotype (A0BB), and $1526 \pm 208 \mathrm{ng} / \mathrm{ml}(95 \% \mathrm{CI}$ : 1079 to $1974 \mathrm{ng} / \mathrm{ml}$ ) for the group with heterozygous C4B null allele. The outcome of the Scheffé multiple comparison procedure (at the $2.5 \%$ level of significance) indicates that the post-protamine $\mathrm{C} 4 \mathrm{a}$ levels in patients with $\mathrm{C} 4$ phenotype $\mathrm{A} 0 \mathrm{BB}$ were significantly higher than those of the group with $\mathrm{C} 4 \mathrm{AABB}$ 


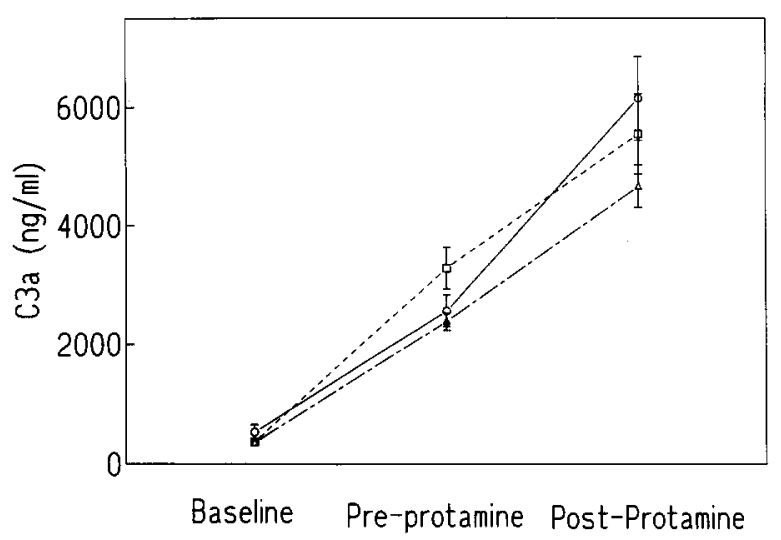

Fig. 2. Influence of $\mathrm{C} 4$ phenotype on complement activation during cardiac operations as measured by $\mathrm{C} 3 \mathrm{a}$ des Arg. C3a levels were measured at different time periods shown on the $\mathrm{X}$ axis; the baseline represents measurements before $\mathrm{CPB}$, pre-protamine indicates measurements at the end of CPB but before protamine, and postprotamine reflects the measurements obtained from blood samples collected 10 minutes after protamine administration. The triangular symbols joined by dashed lines represent patients with normal $\mathrm{C} 4$ phenotype (AABB), open circles with solid lines represent patients with single $\mathrm{C} 4 \mathrm{~A}$ null allele $(\mathrm{A} 0 \mathrm{BB})$, and square symbols with dotted lines show the data on patients with single $C 4 B$ null allele (AAB0). The error bars for each data point represent standard error of mean. Although C3a levels increased at the pre-protamine and the post-protamine time points, the differences between the patient groups did not reach significance (see text).

and the group with $\mathrm{C} 4 \mathrm{AAB} 0$ phenotype. No difference was noted between the latter two groups. Furthermore, patient age, body surface area, protamine dose, and CPB time had no influence on the aforementioned conclusions. Potential misclassification of two patients ( $3 \%$ incidence of $\mathrm{A0B} 0$ ) of the AABB group would not have altered these conclusions even if these patients had the lowest C4a levels of the AABB group.

The $\mathrm{C} 3 \mathrm{a}$ levels after protamine infusion for the three groups were $4667 \pm 360 \mathrm{ng} / \mathrm{ml}$ (95\% CI: 3939 to $5394 \mathrm{ng} / \mathrm{ml}$ ) for the group with a complete set of C4 alleles, $6152 \pm 707 \mathrm{ng} / \mathrm{ml}$ (95\% CI: 4661 to 7643 ) for the group with heterozygous C4A null phenotype, and $5548 \pm 677 \mathrm{ng} / \mathrm{ml}$ (95\% CI: 4105 to 6992 $\mathrm{ng} / \mathrm{ml}$ ) for the group with heterozygous C4B null phenotype. Although the group with $\mathrm{C} 4 \mathrm{~A}$ null phenotype tended to have higher levels of $\mathrm{C} 3 \mathrm{a}$, significant differences among the three groups were not detected when subjected to the Scheffé multiple comparison procedure.

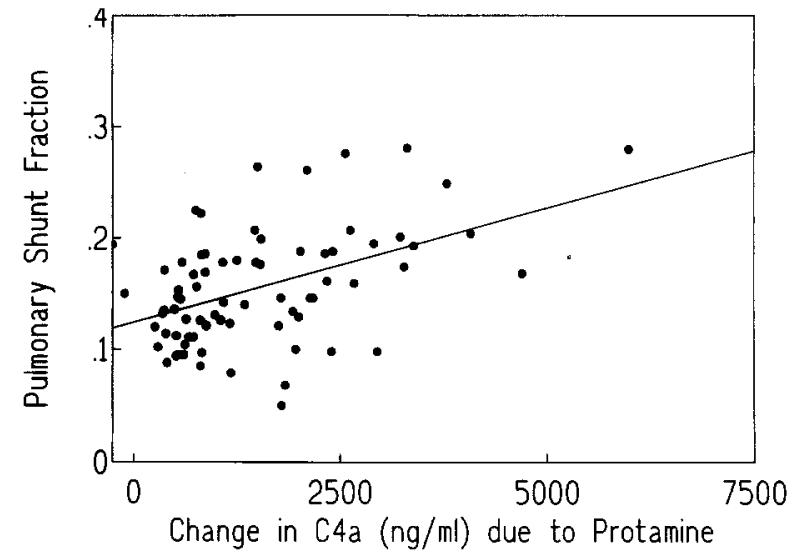

Fig. 3. Effect of complement activation during heparinprotamine interaction on postoperative pulmonary shunt fraction: Pulmonary shunt fractions were calculated from arterial and mixed venous blood gases 16 to 18 hours after the operation and correlated with complement activation by heparin-protamine interaction as measured by change in $\mathrm{C} 4 \mathrm{a}$ levels resulting from protamine administration (i.e., difference in $\mathrm{C} 4 \mathrm{a}$ levels before and after protamine). The solid line represents the regression line of the association $(r=0.473 ; p=0.0001)$.

The clinical parameters of physiologic (pulmonary) shunt fractions were calculated in each patient from arterial and mixed venous blood gases ob- . tained 6 to 8 hours and 16 to 18 hours after the operation. Fig. 3 shows the results of pulmonary shunt fractions 16 to 18 hours after surgery, plotted against the rise in $\mathrm{C} 4 \mathrm{a}$ levels caused by protamine infusion (i.e., the difference in $\mathrm{C} 4 \mathrm{a}$ levels after protamine and one obtained at the end of CPB before protamine administration). As shown, a correlation existed between the two parameters ( $r=$ $0.47, p=0.0001)$. After we had controlled for age, body surface area, dose of protamine, and CPB time, the correlation coefficient was similar $(r=$ $0.49)$. Similarly, shunt fractions at this time period correlated with the absolute $\mathrm{C} 4 \mathrm{a}$ levels after protamine administration $(r=0.43, p=0.001)$. There was also a correlation between the shunt fractions obtained 6 to 8 hours after the operation with both the C4a levels ( $r=0.34, p=0.002$ ) and the difference in the $\mathrm{C} 4 \mathrm{a}$ levels obtained before and after protamine infusion $(r=0.33, p=0.003)$. In contrast to the positive correlation between complement activation by heparin-protamine interaction and shunt fractions, no correlation was seen between the shunt fractions and the alternative pathway complement activation occurring during CPB, as measured by the C3a levels at the end of CPB but 
before protamine administration $(r=0.078$ for shunt fraction at 6 to 8 hours and $r=0.079$ for shunt fraction at 16 to 18 hours).

\section{Discussion}

The present study shows that patients with heterozygous C4A null phenotype have more activation of the classic complement pathway after protamine administration than those with other $\mathrm{C} 4$ phenotypes. It also shows that heparin-protamine complexes make a substantial contribution to complement activation during cardiac operations and that this complement activation is associated with pathophysiologic effects as judged by pulmonary shunt fractions.

Heparin-protamine complexes activate complement by the classic pathway. ${ }^{2-5,13}$ Although considerable information about heparin and protamine individually is available in the literature, much less is known about the configuration, size, composition, and fate of heparin-protamine complexes. Because of their charge, they may adsorb or bind to different blood components. Previous studies have demonstrated the presence of immunoglobulins in the matrix of heparin-protamine complexes. ${ }^{5,14}$ In vitro studies also show that the immunoglobulins bound to heparin-protamine complexes enhance the resulting complement activation. ${ }^{5}$ However, the role of activated $\mathrm{C} 4$ binding in subsequent clearance of these complexes is not known. Animal studies have shown clearance of heparin-protamine complexes in the liver, ${ }^{15}$ but whether they first bind to red cell complement receptors is unknown.

The fourth component of complement plays an important role not only in the classic pathway of complement activation, but also in the clearance of the activating complexes. Its two isotypes, $\mathrm{C} 4 \mathrm{~A}$ and $\mathrm{C} 4 \mathrm{~B}$, differ in their binding characteristics after activation. Activated $\mathrm{C} 4 \mathrm{~A}$ binds more effectively to immune complexes and plays an important role in their clearance, whereas activated $\mathrm{C} 4 \mathrm{~B}$ has more affinity for red cell membranes. ${ }^{8}$ Another noteworthy feature of $\mathrm{C} 4$ is the remarkable incidence of null alleles. Awdeh and Alper, ${ }^{7}$ in their study of 100 randomly selected white persons, found 20 subjects with a single $\mathrm{C} 4 \mathrm{~A}$ null allele (our $\mathrm{A0BB}$ designation). Eighteen of our 79 patients had C4A null allele. In individuals with normal expression of both $\mathrm{C} 4$ isotypes (AABB group), the ratio of $\mathrm{C} 4 \mathrm{~A}$ and $\mathrm{C} 4 \mathrm{~B}$ is approximately 1 . Lack of expression of one allele of $\mathrm{C} 4 \mathrm{~A}$ or $\mathrm{C} 4 \mathrm{~B}$ isotype $(\mathrm{A} 0 \mathrm{BB}$ or $\mathrm{AAB} 0$ ) would reduce the expression of $\mathrm{C} 4 \mathrm{~A}$ or $\mathrm{C} 4 \mathrm{~B}$ by approximately half. ${ }^{9}$ If $\mathrm{C} 4 \mathrm{~A}$ plays as important a role in clearance of heparin-protamine complexes as it does for immune complexes, then C4A null phenotype can have a significant effect on complement activation by heparin-protamine complexes.

In our study, the effect of C4A null allele was increased complement activation of the classic pathway resulting from heparin-protamine interaction in comparison with the group with normal phenotype and that with $\mathrm{C} 4 \mathrm{~B}$ null allele. Although the $\mathrm{C} 4 \mathrm{~A}$ null group also had a greater increase in $\mathrm{C} 3 \mathrm{a}$ levels after protamine than the other two groups, this difference did not reach statistical significance on multiple comparison tests. Because the level of $\mathrm{C} 3 \mathrm{a}$ reflects activation of both the alternative and the classic pathways, it is less sensitive than $\mathrm{C} 4 \mathrm{a}$ to changes exclusively affecting the classic pathway.

One explanation for the increased complement activation by heparin-protamine complexes in patients with C4A null allele could be the reduced clearance of these complexes. With the reduced C4A subcomponent, less activated C4 may be bound to the heparin-protamine complexes or to its other attached proteins. Thus their clearance, which depends on activated $\mathrm{C} 4(\mathrm{C} 4 \mathrm{~b})$ and $\mathrm{C} 3(\mathrm{C} 3 \mathrm{~b})$ binding, is reduced. This reduced clearance may allow the heparin-protamine complexes to stay in circulation, thereby activating more complement and generating more C4a and C3a. This paradox of increased fluid phase complement activation with decreased binding of activated components has been shown to occur with some immune complexes. ${ }^{16}$

The role and effectiveness of complement activation by heparin-protamine complexes in producing adverse effects is the subject of controversy. The reason is that protamine itself may induce transient acute hemodynamic changes ${ }^{17}$ and also may produce allergic reactions. ${ }^{18}$ Although complement activation by heparin-protamine complexes has been recognized, the relative contribution of this activation in producing pathophysiologic effects has not been addressed in most studies. It is necessary that complement cascade proceed beyond $\mathrm{C} 3$ activation if a particular mechanism of complement activation is to be deemed significant. Although C3a and C4a are useful markers of in vivo complement activation, the mediation of inflammation occurs mainly by C5a, a complement split product generated further along the complement cascade. ${ }^{19}$ The value of fluid phase measurement of this extremely potent vasoactive peptide to gauge in vivo complement activation is negated by its rapid binding to receptors on neutrophils and monocytes. ${ }^{20}$ However, it can be 
measured to indicate complement activation in vitro when leukocyte-free plasma or serum is used in experimental manipulations. In our previous studies, C5a could indeed be generated during complement activation induced by the heparin-protamine complex in whole human serum when red cells were present in the reaction mixture. ${ }^{13}$

The present study shows that complement activation by heparin-protamine complexes has delayed pathophysiologic consequences in lung function that are evident even 16 to 18 hours after the operation. In a study by Ranucci and associates, ${ }^{21}$ pulmonary shunt fraction was judged to be the best index of determining the lung dysfunction after cardiac operations. They also noted that in their patient population, free of preoperative lung dysfunction, changes in shunt fraction did not result in delay of extubation or discharge from the intensive care unit. As in their study, our patient population was selected to have normal preoperative pulmonary status and only one of our patients required more than 24 hours of intubation. However, as these authors point out, the observed differences in shunt fractions could potentially result in a different clinical course in patients with preexisting lung dysfunction.

There are some caveats in the interpretations of the present study. We did not perform deoxyribonucleic acid analysis, and we inferred the genotype from phenotypic studies. However, the reduction in the relative concentration of a particular $\mathrm{C} 4$ type, identified by our phenotypic studies, is probably of pathophysiologic relevance, as discussed here. We cannot exclude the possibility that other associated genetic differences may also contribute to the differences seen. We also did not measure the activation of the terminal attack complex. Although we detected an association between the postoperative shunt fractions and $\mathrm{C} 4 \mathrm{a}$ levels generated by protamine interaction with heparin, the differences in shunt fractions among patients could be due to postoperative factors not measured in our study.

Although a probable explanation for the differences in complement activation of the classic pathway between patients of different $\mathrm{C} 4$ isotypes is the reduced clearance of heparin-protamine complexes, the present study did not measure their clearance. Future studies specifically investigating the clearance of heparin-protamine complexes in patients with different $\mathrm{C} 4$ isotypes are warranted. Annually, in excess of 500,000 patients worldwide have heparin-protamine complexes formed in vivo after CPB, and very little is known about the fate of these complexes once they are formed.

We express our sincere gratitude to Deborah M. Bagley of the Center for Blood Research, Boston, Mass., for providing the reference plasma for $\mathrm{C} 4$ typing, as well as for invaluable technical advice. We also acknowledge Ms. Judith Colby and Mr. Edward Johnson for technical assistance and Robert Dunford, MA, for statistical advice.

\section{REFERENCES}

1. Kirklin JK, Westaby S, Blackstone EH, Chenoweth DE, Pacifico AD. Complement and the damaging effects of cardiopulmonary bypass. J Thorac Cardiovasc Surg 1983;86:845-57.

2. Kirklin JK, Chenoweth DE, Naftel DC, Blackstone EH, Kirklin JW, Bitran DD, et al. Effects of protamine administration after cardiopulmonary bypass on complement, blood elements, and the hemodynamic state. Ann Thorac Surg 1986;41:193-9.

3. Cavarocchi NC, Schaff HV, Orszulak TA, Homberger HA, Schnell WA Jr, Pluth JR. Evidence for complement activation by protamine-heparin interaction after cardiopulmonary bypass. Surgery 1985;98:525-31.

4. Rent R, Ertel N, Eisenstein R, Gewurz H. Complement activation by interaction of polyanions and polycations. I. Heparin-protamine induced consumption of complement. J Immunol 1975;114(1 pt 1):120-4.

5. Fiedel BA, Rent R, Myhrman R, Gewurz H. Complement activation by interaction of polyanions and polycations. II. Precipitation and role of $\mathrm{IgG}, \mathrm{Clq}$ and $\mathrm{Cl}-\mathrm{INH}$ during heparin-protamine-induced consumption of complement. Immunology 1976;30:161-9.

6. Davies KA, Schefferli JA, Walport MJ. Complement deficiency and immune complex disease. Springer Semin Immunopathol 1994;15:397-416.

7. Awdeh ZL, Alper CA. Inherited structural polymorphism of the fourth component of human complement. Proc Natl Acad Sci U S A 1980;77:3576-80.

8. Law SKA, Dodds AW, Porter RR. A comparison of the properties of two classes, $\mathrm{C} 4 \mathrm{~A}$ and $\mathrm{C} 4 \mathrm{~B}$, of the human complement component C4. EMBO J 1984;3:1819-23.

9. Awdeh ZL, Raum D, Alper CA. Genetic polymorphism of human complement $\mathrm{C} 4$ and detection of heterozygotes. Nature 1979;282:205-7.

10. Bagley DM, Alper CA. Methods for allotyping complement proteins. In: Rose NR, De Macario EC, Fahey JL, Friedman H, Penn GM. editors. Manual of clinical laboratory immunology. 4th ed. Washington DC: American Society of Microbiology; 1992. p. 124-41.

11. Mauff G, Alper CA, Dawkins R, Doxiadis G, Giles CM, Hauptmann G, et al. C4 nomenclature statement (1990). Complement Inflamm 1990;7:261-8.

12. Shapiro BA, Harrison RA, Cane RD, Kozlowski-Templin R. Applying the physiologic shunt. In: Shapiro BA, Harrison RA, Cane RD, Kozlowski-Templin R, editors. Clinical application of blood gases. 4th ed. Chicago: Year Book; 1989. p. 144-63.

13. Shastri KA, Phillips MJ, Raza S, Logue GL, Rustagi PK. Effect of RBC's on the activation of human complement by heparin-protamine complexes. Blood 1988;71: $36-40$. 
14. Rossmann P, Vetvicka V. Phagocytosis of protamine-heparin aggregates by mouse peritoneal exudate cells. Folia Microbiol (Praha) 1985;30:319-26.

15. Stehle G, Wunder A, Sinn H, Schrenk HH, Friedrich EA, Demple CE, et al. Complexes of a modified low-molecularweight heparin with protamine are predominantly cleared by a macrophage scavenger receptor mediated process in rats. J Surg Res 1995;58:197-204.

16. Ng YC, Peters DK, Walport MJ. Monoclonal rheumatoid factor-IgG immune complexes: poor fixation of opsonic $\mathrm{C} 4$ and C3 despite efficient complement activation. Arthritis Rheum 1988;31:99-107.

17. Wakefield TW, Ucros I, Kresowik TF, Hinshaw DB, Stanley JC. Decreased oxygen consumption as a toxic manifestation of protamine sulfate reversal of heparin anticoagulation. $\mathbf{J}$ Vasc Surg 1989;9:772-7.
18. Weiss ME, Nyhan D, Peng Z, Horrow JC, Lowenstein E, Hirshman $C$, et al. Association of protamine $\operatorname{IgE}$ and $\operatorname{IgG}$ antibodies with life-threatening reactions to intravenous protamine. N Engl J Med 1989;320:886-92.

19. Rinder CS, Rinder HM, Smith BR, Fitch JC, Smith MJ, Tracey JB, et al. Blockade of C5a and C5b-9 generation inhibits leukocyte and platelet activation during extracorporeal circulation. J Clin Invest 1995;96:1564-72.

20. Chenoweth DE, Cooper SW, Hugli TE, Stuart RW, Blackstone EH, Kirklin JW. Complement activation during cardiopulmonary bypass: evidence for generation of $\mathrm{C} 3 \mathrm{a}$ and C5a anaphylatoxins. N Engl J Med 1981;304:497-503.

21. Ranucci M, Cirri S, Conti D, Ditta A, Boncilli A, Frigiola A, et al. Beneficial effects of Duraflo II heparin-coated circuits on postperfusion lung function. Ann Thorac Surg 1996;61: 76-81.

\section{Bound volumes available to subscribers}

Bound volumes of The Journal of Thoracic and Cardiovascular Surgery are available to subscribers (only) for the 1997 issues from the Publisher, at a cost of $\$ 110.50$ for domestic, $\$ 139.64$ for Canadian, and $\$ 130.50$ for international subscribers for Vol. 113 (January-June) and Vol. 114 (July-December). Shipping charges are included. Each bound volume contains a subject and author index and all advertising is removed. Copies are shipped within 60 days after publication of the last issue of the volume. The binding is durable buckram with the Journal name, volume number, and year stamped in gold on the spine. Payment must accompany all orders. Contact Mosby-Year Book, Inc., Subscription Services, 11830 Westline Industrial Drive, St. Louis, Missouri 63146-3318, USA; phone $800-453-4351$ or $314-453-4351$.

Subscriptions must be in force to qualify. Bound volumes are not available in place of a regular Journal subscription. 